\title{
Peningkatan Kesadaran Hukum Tentang Konservasi Lingkungan Bagi Masyarakat Watutela
}

\author{
Agus Lanini' ${ }^{1}$, Ikhsan Syafiuddin ${ }^{2}$ \\ 1,2 rogram Studi Ilmu Hukum Fakultas Hukum Universitas Tadulako \\ *e-mail: aguslanini@untad.ac.id ${ }^{1}$, ikhsansyafruddin@untad.ac.id²
}

\begin{abstract}
Watutela group of farmers and ranchers, who are very vulnerable to various problems of forest destruction. Lack of public understanding of the prohibition of illegal logging of forest trees in forest areas (Grand Forest Park). Seeing this situation, the increase in legal awareness, especially understanding of the legal obligations to conserve forests with the status of a grand forest park area. The method of implementing the activity begins with field observations, then makes contact with the head of the RW for administrative purposes, determining the time for activities and invitations to prospective participants in focus group discussions. The participatory discussion method was carried out in the afternoon. It can be said that the level of understanding of the community in the sense of complying with the provisions of forest conservation is still low, after the activity appears perceptions and attitudes that are in line with the provisions of conservation so that a commitment is built to maintain the sustainability of the forest while still benefiting (symbiosis mutualism).
\end{abstract}

Keywords: Increasing, legal awareness, environmental conservation.

\begin{abstract}
Abstrak
Kelompok petani dan peternak Watutela, yang sangat rentan dengan berbagai masalah kerusakan hutan. Kurangnya pemahaman masyarakat terhadap larangan penebangan pohon-pohon kayu dalam kawasan hutan (taman hutan raya) secara liar. Melihat keadaan tersebut, maka peningkatan kesadaran hukum khususnya pemahaman terhadap kewajiban hukum untuk melakukan konservasi hutan yang berstatus kawasan taman hutan raya. Metode pelaksanaan kegiatan diawali dengan observasi lapangan, kemudian melakukan kontak dengan pihak ketua RW untuk keperluan administrasi, penentuan waktu kegiatan dan undangan kepada calon peserta diskusi kelompok terfokus. Metode diskusi partisipatif dilaksanakan pada sore hari. Dapat dikatakan bahwa tingkat pemahaman warga masyarakat dalam arti mematuhi ketentuan konservasi hutan masih rendah, setelah kegiatan tersebut muncul persepsi dan sikap yang bersuaian dengan ketentuan konservasi sehingga terbangun komitmen untuk bersama-sama menjaga kelestarian hutan dengan tetap mendapat manfaatnya (symbiosis mutualisme).
\end{abstract}

Kata Kunci: Peningkatan, kesadaran hukum, konservasi lingkungan.

\section{PENDAHULUAN}

Watutela dikenal sebagai salah satu kampung dari Kelurahan Tondo wilayah Kecamatan Mantikulore, berjarak sekitar $\pm 8 \mathrm{~km}$ dari Kota Palu, Provinsi Sulawesi Tengah. Watutela dikenal pula dengan sebutan RW 13 di Kelurahan Tondo. Wilayah kampung ini merupakan salah satu daerah aliran sungai dan pinggiran taman hutan raya (Tahura). Kini jumlah penduduk yang bermukim di wilayah Watutela sekitar 350 kepala keluarga. Mata pencaharian penduduknya umumnya bertani dan berternak. Namun areal pertanian yang subur semakin sempit seiring dengan pertambahan penduduk yang semakin pesat (Sfandy Rusly; Budiman; Nur Rismawati, 2019).

Sementara taman hutan raya yang berbatasan dengan kampung ini tidak dapat dikelola berdasarkan adanya ketentuan kawasan hutan, yang melarang adanya aktifitas lain seperti kegiatan pertanian dalam kawasan. Undang-Undang No 41 Tahun 1999 tentang Kehutanan. Dalam Pasal 50 ayat (1) dan (3) dinyatakan bahwa Setiap orang dilarang merusak prasarana dan sarana perlindungan hutan. Kemudian setiap orang dilarang mengerjakan dan atau menggunakan dan atau menduduki kawasan hutan secara tidak sah termasuk merambah kawasan hutan dan sejumlah bentuk larangan lainnya (J. Lahandu, Tarumingkeng, \& Kartodihardjo, 2016). 
Hal tersebut menurut undang-undang kehutanan sebagai bentuk penyelenggaraan perlindungan hutan dan konservasi alam yang bertujuan menjaga hutan, kawasan hutan dan lingkungannya, agar fungsi lindung, fungsi konservasi, dan fungsi produksi, tercapai secara optimal dan lestari.

Konservasi merupakan bagian yang tidak terpisahkan dari pengelolaan sumber kehidupan masyarakat. Integritas sebuah kawasan hutan dimasa yang akan datang, tidak hanya tergantung kepada efektifitas pelaksanaan konservasi, akan tetapi juga kepada dukungan masyarakat lokal dalam pengelolaan seumber daya alamnya (Djafar Mey, 2010; Manurung \& Sunarta, 2016; Safira, Wulandari, \& Kaskoyo, 2017).

Warga masyarakat kampung Watutela, berada pada dua keadaan yang sama sulitnya yaitu pemenuhan kebutuhan hidup dari kegiatan pertanian tetapi memasuki kawasan hutan (taman hutan raya). Sementara mereka juga harus mematuhi ketentuan perundang-undangan yang nyata mengancam jika terjadi tindakan yang melanggarnya berupa sanksi pidana (Azmi Sirajuddin, 2012; Nuraedah, 2014; Rosana, 2019; Wenda Hartanto, 2015).

Kondisi tersebut memerlukan solusi secara nyata bagi masyarakat Kampung Watutela yang mengantungkan sumber kehidupannya pada alam atau hasil pertanian dan peternakan. Kesemuanya hanya mungkin berlangsung dengan baik jika sumber air yang berasal dari tangkapan pohon-pohon atau tumbuhan yang hidup dalam taman hutan raya tetap dilestarikan (J. Lahandu et al., 2016; Masdar \& Zaiful, 2011; Sfandy Rusly; Budiman; Nur Rismawati, 2019).

Permasalahnnya jika pemahaman atau kesadaran masayarakat yang telah dipengaruhi modernisasi tekonologi dan kebutuhan hidup serta ekonomi yang semakin meningkat, menyebabkan sikap mereka menjadi pragmatis. Maka hutan menjadi sasaran atau objek pemenuhan tuntutan modernisasi dan kepentingan ekonomi tersebut. Akibatnya ditemukan sejumlah petak/ blok dari kawasan hutan telah ditebang dan dibakar, sebahagian lainnya telah menjadi ladang dan berisi tanaman keras seperti coklat, kemiri, dan mangga serta tanaman hortikultura lainnya (A.M. Yunus Wahid, 2018; Soerjono Soekanto, 2014).

\section{METODE PENGABDIAN}

Kegiatan pengabdian ini menggunakan metode ceramah, simulasi dan participatory rural appraisal (PRA) melalui kegiatan ini dapat diketahui kendala-kendala dan harapan yang dihadapi oleh masyarakat khususnya yang bekerja sebagai petani dan peternak, sehingga hasil dari diskusi tersebut dapat dijadikan bahan atau materi diskusi sehingga sesuai dengan kebutuhan peserta.

Metode ceramah hanya diberikan untuk penyampaian materi pokok yang bersifat teoritis, dengan mengundang satu orang untuk menjadi narasumber yang kompeten di bidang hukum dan konservasi, kemudian dilanjutkan dengan sesi diskusi/ tanya jawab.

Focus Group Discussion; metode ini dilakukan dengan membagi peserta dalam bentuk kelompok, dimana setiap kelompok akan berdiskusi ditunjuk satu orang ketua dan satu orang sekretaris. Diskusi kelompok dipandu oleh seorang pemandu atau fasilitator, peserta diskusi kemudian mengerjakan tugas yang diberikan secara bersama-sama.

Notulen mencatat semua informasi dan data yang relevan termasuk solusi yang disepakati oleh semua kelompok peserta diskusi. Untuk kelengkapan catatan notulensi didukung dengan dokumentasi berupa foto-foto dan hasil kerja kelompok diskusi.

\section{HASIL DAN PEMBAHASAN}

\section{Pelaksanaan Kegiatan Peningkatan Pemahaman Tentang Ketentuan Hukum Konservasi Lingkungan}

Dinamika diskusi kelompok terfokus perihal hutan konservasi sangat tinggi, karena hal tersebut berkaitan dengan kepentingan mendasar yang hamper seluruh peserta mempunyai 
keinginan yang sama untuk mendapat manfaat dari adanya Kawasan hutan tersebut. Nilai yang terdapat atau diperoleh dari hutan tersebut menjadi perhatian utama peserta diskusi .

Meskipun sejumlah anggapan bahwa hutan itu dapat digunakan hasilnya berupa kayu atau non kayu oleh siapa saja tetapi ternyata mereka juga merasa kuatir jika melakukan Tindakan yang kemudian ditenggarai sebagai perbuatan melawan hukum sehingga terlontar ungkapan keberatan atas aturan yang secara tegas membatasi bahkan melarang melakukan aktifitas dalam hutan (Kamarullah; Nafsiatun; Hendri \& Widiyantoro, 2019; J. S. U. sulaiman M. H. K. Lahandu, 2018).

Secara riil peserta diskusi tidak mengetahui bunyi ketentuan hukum yang mengatur Kawasan hutan/ taman hutan raya, namun berdasarkan informasi dari mulut ke mulut bahwa ancaman hukuman badan berupa pemidanaan (penjara) dapat dijatuhkan jika terbukti melakukan Tindakan yang melanggar ketentuan hukum di bidang kehutanan.

Narasumber kemudian menjelaskan maksud dan tujuan dari adanya larangan untuk melakukan kegiatan yang merusak atau mengganggu fungsi Kawasan hutan/ taman hutan raya Palu. Hal tersebut secara tegas di atur dalam Undang-Undang No. 41 Tahun 1999 tentang Kehutanan (selanjutnya disingkat UU Kehutanan). Dimana dalam Pasal 46 UU Kehutanan dinyatakan, "Penyelenggaraan perlindungan hutan dan konservasi alam bertujuan menjaga hutan, kawasan hutan dan lingkungannya, agar fungsi lindung, fungsi konservasi, dan fungsi produksi, tercapai secara optimal dan lestari". Hal yang sama ditegaskan juga dalam UU No. 32 Tahun 2009 Tentang Perlindungan dan Pengelolaan Lingkungan (UUKehutanan, 1999; UUPPLH, 2009).

Kemudian pada Pasal 47 UU Kehutanan disebutkan bahwa Perlindungan hutan dan kawasan hutan merupakan usaha untuk:

a. Mencegah dan membatasi kerusakan hutan, kawasan hutan, dan hasil hutan yang disebabkan oleh perbuatan manusia, ternak, kebakaran, daya-daya alam, hama, serta penyakit; dan

b. Mempertahankan dan menjaga hak-hak negara, masyarakat, dan perorangan atas hutan, kawasan hutan, hasil hutan, investasi serta perangkat yang berhubu ngan dengan pengelolaan hutan.

Selanjutnya dalam Pasal 51UU Kehutanan disebutkan:

(1) Untuk menjamin terselenggaranya perlindungan hutan, maka kepada pejabat kehutanan tertentu sesuai dengan sifat pekerjaannya diberikan wewenang kepolisian khusus.

(2) Pejabat yang diberi wewenang kepolisian khusus sebagaimana dimaksud pada ayat (1) berwenang untuk:

a. mengadakan patroli/perondaan di dalam kawasan hutan atau wilayah hukumnya;

b. memeriksa surat-surat atau dokumen yang berkaitan dengan pengangkutan hasil hutan di dalam kawasan hutan atau wilayah hukumnya;

c. menerima laporan tentang telah terjadinya tindak pidana yang menyangkut hutan, kawasan hutan, dan hasil hutan;

d. mencari keterangan dan barang bukti terjadinya tindak pidana yang menyangkut hutan, kawasan hutan, dan hasil hutan;

e. dalam hal tertangkap tangan, wajib menangkap tersangka untuk diserahkan kepada yang berwenang; dan

f. membuat laporan dan menandatangani laporan tentang terjadinya tindak pidana yang menyangkut hutan, kawasan hutan, dan hasil hutan.

Setelah mendapat penjelasan tersebut, peserta mengajukan sejumlah pertanyaan yang terkait dengan mata pencaharian mereka sebagai petani dan peternak. Bahwa tujuan pemerintah sebenarnya baik namun tidak memberi akses pada masyarakat Watutela untuk memanfaatkan sumberdaya hutan yang sangat mereka butuhkan. 

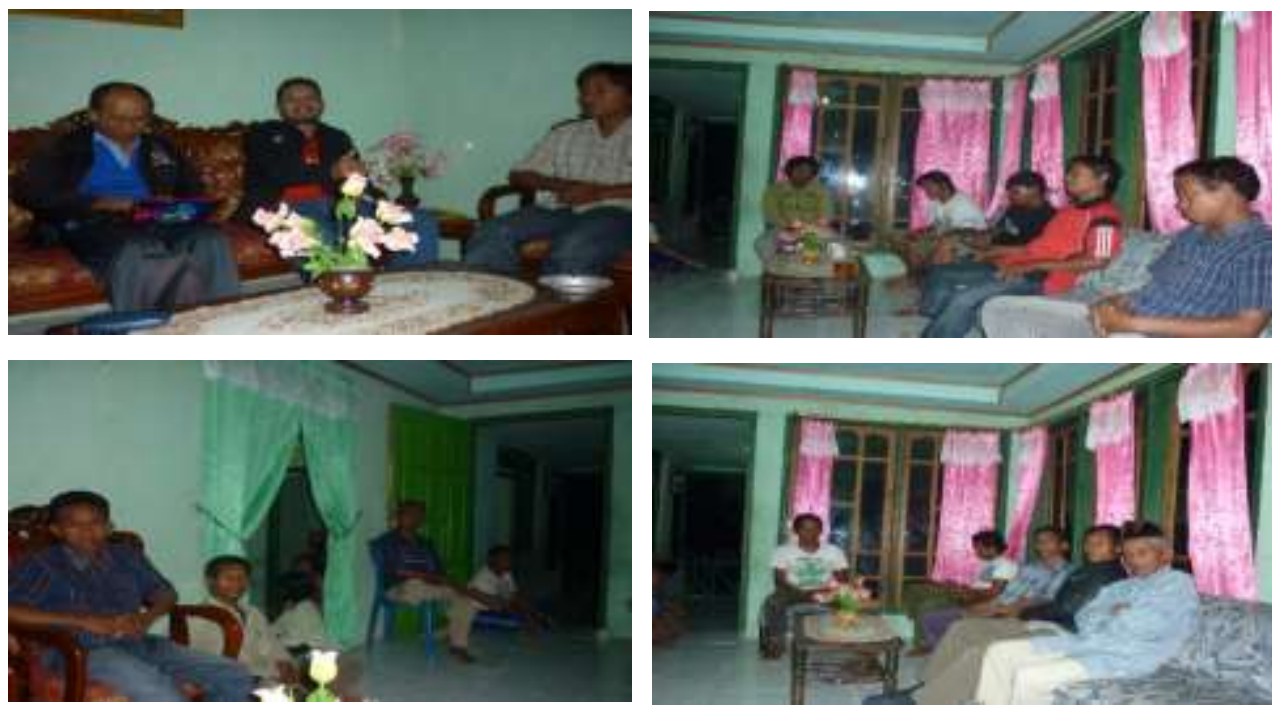

Gambar 1. Foto suasana kegiatan diskusi kelompok terfokus di rumah ketua rukun warga (RW)

\section{Kepatuhan Hukum Masyarakat Watutela dalam Pelaksanaan Konservasi Taman Hutan Raya Palu}

Perilaku hukum masyarakat Watutela terhadap ketentuan perlindungan sumberdaya hutan dapat dilihat dari adanya sejumlah kegiatan yang terkait dengan pemanfaatan bahkan perusakan beberapa bagian/blok dari taman hutan raya. Dalam diskusi kelompok terfokus terungkap meskipun tidak secara terang-terangan peserta menyebut adanya sejumlah warga yang membuka ladang/ kebun di sekitar pinggiran taman hutan raya.

Namun ketika dijelaskan tentang adanya sejumlah larangan dalam kawasan hutan, bahwa dalam Pasal 50 UU Kehutanan ditegaskan:

(1) Setiap orang dilarang merusak prasarana dan sarana perlindungan hutan.

(2) Setiap orang yang diberikan izin usaha pemanfaatan kawasan, izin usaha pemanfaatan jasa lingkungan, izin usaha pemanfaatan hasil hutan kayu dan bukan kayu, serta izin pemungutan hasil hutan kayu dan bukan kayu, dilarang melakukan kegiatan yang menimbulkan kerusakan hutan.

(3) Setiap orang dilarang:

a. mengerjakan dan atau menggunakan dan atau menduduki kawasan hutan secara tidak sah;

b. merambah kawasan hutan;

c. melakukan penebangan pohon dalam kawasan hutan dengan radius atau jarak sampai dengan:

1. 500 (lima ratus) meter dari tepi waduk atau danau;

2. 200 (dua ratus) meter dari tepi mata air dan kiri kanan sungai di daerah rawa;

3. 100 (seratus) meter dari kiri kanan tepi sungai;

4. 50 (lima puluh) meter dari kiri kanan tepi anak sungai;

5.2 (dua) kali kedalaman jurang dari tepi jurang;

6. 130 (seratus tiga puluh) kali selisih pasang tertinggi dan pasang terendah dari tepi pantai.

d. membakar hutan;

e. menebang pohon atau memanen atau memungut hasil hutan di dalam hutan tanpa memiliki hak atau izin dari pejabat yang berwenang;

f. menerima, membeli atau menjual, menerima tukar, menerima titipan, menyimpan, atau memiliki hasil hutan yang diketahui atau patut diduga berasal dari kawasan hutan yang diambil atau dipungut secara tidak sah; 
g. melakukan kegiatan penyelidikan umum atau eksplorasi atau eksploitasi bahan tambang di dalam kawasan hutan, tanpa izin Menteri;

h. mengangkut, menguasai, atau memiliki hasil hutan yang tidak dilengkapi bersama-sama dengan surat keterangan sahnya hasil hutan;

i. menggembalakan ternak di dalam kawasan hutan yang tidak ditunjuk secara khusus untuk maksud tersebut oleh pejabat yang berwenang;

j. membawa alat-alat berat dan atau alat-alat lainnya yang lazim atau patut diduga akan digunakan untuk mengangkut hasil hutan di dalam kawasan hutan, tanpa izin pejabat yang berwenang;

k. membawa alat-alat yang lazim digunakan untuk menebang, memotong, atau membelah pohon di dalam kawasan hutan tanpa izin pejabat yang berwenang;

l. membuang benda-benda yang dapat menyebabkan kebakaran dan kerusakan serta membahayakan keberadaan atau kelangsungan fungsi hutan ke dalam kawasan hutan; dan

m. mengeluarkan, membawa, dan mengangkut tumbuh-tumbuhan dan satwa liar yang tidak dilindungi undang-undang yang berasal dari kawasan hutan tanpa izin dari pejabat yang berwenang.

(4) Ketentuan tentang mengeluarkan, membawa, dan atau mengangkut tumbuhan dan atau satwa yang dilindungi, diatur sesuai dengan peraturan perundang-undangan yang berlaku.

Peserta diskusi menyimak penjelasan ketentuan hukum tersebut, namun ada juga yang penasaran untuk bertanya kaitannya dengan kondisi yang terjadi di kawasan taman hutan raya. Selain itu muncul usulan tentang pemanfaatan pinggiran hutan secara tidak merusak, sebab sulit untuk mencari lokasi lain selain kawasan tersebut.

Diskusi kelompok terfokus ini merupakan salah satu cara yang dipandang cukup efektif dalam rangka mengkomunikasikan hukum kepada masyarakat demikian pula pengabdi dapat menyerap aspirasi mereka. Hal tersebut tersebut dimaksudkan agar warga masyarakat dapat memahami, arti, isi dan makna hukum tersebut bertujuan untuk mencapai kadar kesadaran hukum yang tinggi dalam masyarakat. Sehingga setiap warga masyarakat taat dan patuh kepada hukum (Achmad Ali, 2010; Yasonna H Laoly, 2011).

Setelah dilakukan evaluasi kegiatan pengabdian pada masyarakat ini, maka diperoleh gambaran bahwa :

1. Jumlah peserta/ sasaran yang ditargetkan setiap penyuluhan sebanyak 25 orang, target tersebut dapat di capai 75\% secara rata-rata selama pelaksanaan kegiatan.

2. Partisipasi kelompok sasaran yang relatif cukup tinggi yang diukur dengan ketetapan waktu dan perhatian yang serius dalam mengikuti penyuluhan/ tanya jawab.

3. Pada umumnya kelompok sasaran telah memiliki pengetahuan dasar atau kemampuan awal tentang materi apa yang disajikan dalam ceramah sehingga memungkinkan terjadinya komunikasi timbal balik yang cukup partisipasif.

Dari hasil evaluasi tersebut diperoleh gambaran bahwa persepsi dan sikap masyarakat terhadap aspek-aspek yang berkaitan dengan masalah ketentuan hukum lingkungan khususnya ketentuan konservasi hutan relatif baik meskipun masih ada juga oknum yang terlibat sebagai pelaku perambah atau perusak hutan.

Yang menjadi faktor penunjang sehingga kegiatan ini dapat berjalan sesuai dengan rencana dapat diidentifikasi beberapa hal yang mendorong masyarakat untuk berpartisipasi dalam kegiatan pengabdian tersebut adalah :

1. Adanya relevansi faktor penunjang antara materi kegiatan dengan kebutuhan kelompok sasaran yang selama ini menjadi pemicu konflik antara kepentingan petani dan peternak di satu pihak, pemerintah, dan kepentingan pihak tertentu.

2. Adanya perhatian yang relatif tinggi dari ketua RW dalam menggerakkan kegiatan yang dimaksud. 
3. Adanya partisipasi secara sukarela dari kelompok petani dan peternak di luar yang menjadi objek sasaran.

Disamping factor penunjang yang telah dikemukakan sebelumnya, maka faktor-faktor yang menjadi penghambat terlaksananya kegiatan pengabdian antara lain:

1. Relatif sulitnya mengumpul penduduk pada saat akan melaksanakan kegiatan yang disebabkan karena sebagian penduduk pada siang hari melaksanakan aktifitas rutinnya seperti ke tempat kerja masing-masing.

2. Kegiatan tidak dapat dilaksanakan setiap hari, sehingga harus menyesuaikan kesediaan waktu luang petani dan peternak artinya kegiatan ini tanpa menyita waktu kerja mereka yang terlalu banyak.

Meskipun demikian, hambatan pelaksanaan kegiatan pengabdian tersebut tidak mengurangi tujuan yang telah ditetapkan yaitu peningkatan pemahaman masyarakat terhadap ketentuan hukum tentang konservasi lingkungan. Setidaknya mereka sudah mempertimbangkan sebelum melakukan kegiatan di sekitar kawasan taman hutan raya.

\section{KESIMPULAN}

Pemahaman atau persepsi dan sikap masyarakat Kampung Watutela terhadap kewajiban hukum konservasi lingkungan baru sebatas apa yang telah dilakukan sehari-hari terhadap lingkungan, mereka belum yakin sepenuhnya dengan perlindungan hukum yang ada (UU Kehutanan/ UU Lingkungan). Setelah kegiatan pengabdian dilaksanakan peserta menunjukan persepsi/sikap yang bersesuaian dengan ketentuan konservasi lingkungan melalui beberapa pernyataan atau komitmen untuk menjaga/ melestarikan lingkungan khususnya kawasan taman hutan raya Kota Palu, namun berharap agar diberi kesempatan untuk dapat memanfaatkan hasilhasil hutan yang ada dalam kawasan tersebut. Termasuk memanfaatkan areal pinggiran hutan untuk bertani.

Peranan pemerintah dirasakan sangat kurang dalam mengurusi berbagai masalah yang dihadapi oleh petani dan peternak. Sementara pihak pihak tertentu termasuk pemodal dinilai lebih banyak mendapat perhatian dan pelayanan pemerintah. Olehnya masih perlu dilakukan serangkaian kegiatan baik non fisik maupun kegiatan fisik untuk mendorong atau memotivasi warga masyarakat Watutela dalam melakukan aktifitas di sekitar kawasan taman hutan raya agar menjaga dan memelihara kelestarian lingkungan. Dalam hal ini peran sekaligus tanggung jawab pemerintah daerah kota Palu sangat menentukan berlangsungnya atau dipatuhinya ketentuan hukum tentang konservasi lingkungan.

\section{UCAPAN TERIMA KASIH}

Terima kasih kepada pimpinan Fakultas Hukum Universitas Tadulako yang telah memfasilitasi kegiatan pengabdian kepada masyarakat melalui alokasi dana BOPTN secara selektif sehingga kegiatan ini dapat dilaksanakan sesuai waktu yang ditentukan.

\section{DAFTAR PUSTAKA}

A.M. Yunus Wahid. (2018). Pengantar Hukum Lingkungan. Kencana (2nd ed., Vol. 2). Jakarta: Prenada Media Group.

Achmad Ali. (2010). Menguak Teori Hukum (Legal Theory) dan Teori Peradilan (Judicial Prudence) Termasuk Interpretasi Undang-Undang (Legisprudence). Kencana (3rd ed., Vol. 1). Jakarta: Prenada Media Group. 
Azmi Sirajuddin. (2012). Ngapa Vatutela Di Antara Tahura dan Tambang. Yayasan Merah Putih, 5.

Djafar Mey. (2010). Konservasi Tanah Berbasis Erosi Di Kawasan Taman Hutan Raya (Tahura) Nipa-Nipa Kota Kendari. AGRIPLUS, 20(2), 170-181.

Kamarullah; Nafsiatun; Hendri, M. I., \& Widiyantoro, A. (2019). Peningkatan Perilaku Peduli Hukum Dan Lingkungan Melalui Program Kemitraan Masyarakat Peduli Hukum. Dinamisia Jurnal Pengabdian Kepada Masyarakat, 3(1), 1-6.

Lahandu, J. S. U. sulaiman M. H. K. (2018). The Access of Kaili Community to the Natural Resource of the Central Sulawesi Grand Forest Park. Journal of Culture Society and Deevelopment, 41, 8-17.

Lahandu, J., Tarumingkeng, R. C., \& Kartodihardjo, H. (2016). Analisis Kebijakan Pengelolaan Akses Sumber Daya Alam oleh Masyarakat Kaili di Tanah Hutan Raya (Tahura) Sulawesi Tengah. Jurnal Agrisains, 17(April), 24-33.

Manurung, V. T., \& Sunarta, I. N. (2016). Konservasi Sumber Daya Taman Hutan Raya Ngurah Rai Sebagai Destinasi Ekowisata. Jurnal Destinasi Pariwisata, 4(2), 20. https://doi.org/10.24843/jdepar.2016.v04.i02.p04

Masdar, R., \& Zaiful. (2011). Perencanaan Keuangan Komunitas Mmiskin di Perkampungan Vatutela. JURNAL ACADEMICA Fisip Untad, 03(01), 615-624.

Nuraedah. (2014). Transformasi Masyarakat Kaili di Kelurahan Tondo. Kreatif, 17(1), 30-39. Retrieved from http://jurnal.untad.ac.id/jurnal/index.php/Kreatif/article/view/3129

Rosana, E. (2019). Kepatuhan Hukum Sebagai Wujud Kesadaran Hukum Masyarakat. Cultural Evolution. https://doi.org/10.7551/mitpress/9894.003.0005

Safira, G. C., Wulandari, C., \& Kaskoyo, H. (2017). Kajian Pengetahuan Ekologi Lokal dalam Konservasi Tanah dan Air di Sekitar Taman Hutan Raya Wan Abdul Rachman. Jurnal Sylva Lestari, 5(2), 23-29. https://doi.org/10.23960/jsl2523-29

Sfandy Rusly; Budiman; Nur Rismawati. (2019). Study Kualitas Air Pada Instalasi Pengolahan Air Vatutela PDAM Kota Palu. Kolaboratif Sains, 1(1), 8. https://doi.org/ https://doi.org/10.31934/jom

Soerjono Soekanto. (2014). Pokok-Pokok Sosiologi Hukum. Rajawali Pers (1st ed.). Jakarta: Rajawali Pers.

UUKehutanan. UURI No. 41 Tahun 1999 Tentang Kehutanan, Pub. L. No. 41 (1999). Indonesia.

UUPPLH. UURI No 32 Tahun 2009 Tentang Perlindungan dan Pengelolaan Lingkungan, Pub. L. No. 32, 2009 Setneg RI 31 (2009). Indonesia.

Wenda Hartanto. (2015). Kesadaran Hukum Sebagai Aspek Dasar Politik Hukum Lesgislasi; Suatu Tinjauan Filsafat. Rechts Vinding, 4(3), 295-310.

Yasonna H Laoly. (2011). Kesadaran Hukum dan Terwujudnya Keadilan Bagi Seluruh Rakyat Indonesia.Jakarta. (https://www.unuja.ac.id/unduh/10/Materi\%20Kuliah\%20Umum\%20 Menkumham.pdf). 